\title{
Prevalensi Fascioliasis pada Kerbau di Kabupaten Agam, Sumatra Barat, Indonesia
}

\author{
Prevalence of Fascioliasis in Buffalo in Agam Regency, \\ West Sumatra, Indonesia
Muhammad Ridwan ${ }^{1 *}$, Lucia Tri Suwanti ${ }^{2}{ }^{(}$, Tri Wahyu Suprayogi $^{3}{ }^{\circledR}$, Mufasirin $^{2}$, Kusnoto $^{2}$ dan Poedji Hastutiek $^{2}$ \\ ${ }^{1}$ Mahasiswa, ${ }^{2 D i v i s i ~ P a r a s i t o l o g i, ~}{ }^{3}$ Divisi Reproduksi \\ Departemen Ilmu Kedokteran Hewan \\ Fakultas Kedokteran Hewan, Universitas Airlangga, \\ Surabaya 60115 \\ *E-mail : muhammad.ridwan-2017@fkh.unair.ac.id
}

\begin{abstract}
ABSTRAK
Salah satu permasalahan yang sering dihadapi para peternak kerbau adalah penyakit Fascioliasis yang disebabkan oleh cacing hati atau Fasciola spp., dimana penyakit tersebut adalah salah satu penyakit yang bersifat zoonosis. Oleh sebab itu penelitian ini bertujuan untuk mengetahui prevalensi Fasciola spp. pada kerbau di Kabupaten Agam, Sumatra Barat. Sampel berupa feses 105 ekor kerbau dari tiga kecamatan lalu diperiksa dengan menggunakan metode natif (sederhana) dan sedimentasi sederhana. Hasil penelitian diperoleh 25 ekor dari 105 ekor kerbau dinyatakan positif terinfeksi Fasciola spp. Prevalensi yang diperoleh secara keseluruhan adalah 23,81\% (25/105), dan hasil ini dapat dikembangkan dalam penelitian lebih lanjut.
\end{abstract}

Kata Kunci: Fasciola spp., Kerbau, Prevalensi.

\begin{abstract}
One of the problems that buffalo farmers often found Fascioliasis caused by liver fluke or Fasciola spp., where the disease is one of the zoonotic diseases. Therefore, this study aims to determine the prevalence of Fasciola spp. in buffalo in Agam Regency, West Sumatra. Samples in the form of feces 105 buffalo from three sub-districts were then examined using native (simple) and sedimentation simple methods. The results of the study obtained 25 of 105 buffaloes were declared positively infected with Fasciola spp. The overall prevalence was $23.81 \%$ (25/105), and these results can be developed in further research.
\end{abstract}

Keyword: Buffalo, Fasciola spp., Prevalence 
Ridwan et al. MKH (2021). 105-113

DOI: $10.20473 / \mathrm{mkh} . v 32 \mathrm{i} 3.2021 .105-113$

\section{PENDAHULUAN}

Kerbau merupakan salah satu ternak ruminansia besar yang sering dipelihara oleh peternak Indonesia dan salah satunya juga banyak ditemukan di wilayah Kabupaten Agam Sumatra Barat. Berdasarkan data statistik yang ada, populasi kerbau di Indonesia mengalami peningkatan yang signifikan dari 894,3 ribu ekor pada tahun 2018 menjadi 1.141,3 ribu ekor pada tahun 2019 (BPS Indonesia, 2020). Peningkatan ini tidak terlepas dari usaha pemerintah dan peternak dalam usaha peningkatan populasi kerbau, namun hal ini sering terhambat oleh munculnya beberapa penyakit salah satunya penyakit parasitik yaitu fascioliasis.

Fascioliasis merupakan penyakit yang memiliki potensi sebagai penyakit zoonosis yang disebabkan oleh cacing hati Fasciola spp. Zoonosis sendiri merupakan penyakit yang menjadi pembicaraan penting di berbagai negara saat ini, dimana penyakit ini dapat ditularkan dan memiliki dampak terhadap manusia seperti menimbulkan kerugian ekonomi, kesakitan, bahkan menyebabkan kematian (Budiono et al., 2018; Khairiyah, 2011). Kejadian fascioliasis pada manusia banyak ditemukan di negara empat musim atau subtropic, namun di Indonesia belum ditemukan laporannya melainkan ditemukan kasus serupa yaitu fasciolopsiasis yang disebabkan oleh Fasciolopsisbuski (Widjajanti, 2004).
Diperkirakan bahwa manusia dapat tertular penyakit fascioliasis karena mengkonsumsi makanan mentah seperti sayur segar yang tidak dimasak dan air mentah yang telah terkontaminasi oleh stadium metaserkaria dari Fasciola spp. sebagai stadium infektifnya (Hambal at al., 2013).

Cacing Fasciola spp. pada kerbau dalam stadium dewasa dapat ditemukan di parenkim hati sehingga menyebabkan kejadian hepatitis parenkimatosa akut dan kholangitis kronis, selain itu infeksi Fasciola spp. juga menyebabkan gangguan pertumbuhan, menurunkan berat badan, menimbulkan anemia hingga menyebabkan kematian (Rana et al., 2014; Hambal et al., 2013). Berbagai hasil penelitian terkait Fasciola spp. terutama pada kerbau yang dilaporkan seperti di Pakistan 42,06\%, Nepal 58,82\%, India 21,19 \%, dan Kecamatan Jati Agung Lampung Selatan 6,25\% (Bhutto et al., 2012; Yadav et al., 2015; Pandya et al., 2015; Ermawati et al., 2020).

Kejadian fascioliasis pada ternak dapat dipengaruhi oleh berbagai faktor risiko seperti spesies, umur, kondisi hewan, cara pemeliharaan, pakan, tipe kandang, sanitasi atau kebersihan, dan konsistensi feses yang cair sehingga mempercepat terjadinya proses penularan Fasciola spp. (Kusnoto et al., 2011; Karim et al., 2016). Banyaknya kerugian yang ditimbulkan baik menyangkut kesehatan hewan maupun kesehatan manusia dari kejadian 
fascioliasis terutama pada kerbau, maka diperlukan adanya penelitian yang bertujuan untuk mengetahui kejadian dan prevalensi Fasciola spp. di Kabupaten Agam, Sumatra Barat, Indonesia, sehingga hasil yang diperoleh dapat dilakukan tindakan pengendalian.

\section{MATERI DAN METODE}

\section{Bahan dan Alat Penelitian}

Bahan dan peralatan yang digunakan dalam penelitian ini berupa sampel feses kerbau, formalin 10\%, aquadest, sarung tangan, masker, cool box, pot sampel, alat pengaduk, kertas label, sendok plastik, object glass, cover glass, pipet Pasteur, tabung sentrifus, saringan, mikroskop, dan sentrifus.

\section{Sampel dan Besar Sampel}

Sampel berupa feses dari kerbau berjumlah 105 ekor yang diperoleh dari rumus Solvin (Umar, 2002) dengan teknik pengambilan sampel random sampling. Jumlah sampel terdiri atas 35 sampel di Kecamatan Candung, 35 sampel di Kecamatan Ampek Angkek, dan 35 sampel di Kecamatan Tilatang Kamang, ketiga daerah ini diambil karena memiliki jumlah populasi kerbau yang cukup banyak sehingga mempermudah dalam pengumpulan sampel.

\section{Prosedur Penelitian}

Penelitian ini berjenis survey dengan rancangan cross sectional study yang merupakan rancangan observasional. Feses diperiksa di UPT Puskeswan Magek dan untuk identifikasi dilakukan di Laboratorium Balai Veteriner Bukittinggi. Penelitian dilaksanakan bulan Agustus sampai November 2020. Feses yang digunakan berupa feses baru keluar setelah defekasi, sebanyak 5-10 gram, lalu dimasukkan ke pot sampel, ditambahkan pengawet agar sampel dapat disimpan lebih lama, dan diberi label.

Pemeriksaan feses dilakukan dengan metode natif (sederhana) dan sedimentasi sederhana karena merupakan metode pemeriksaan rutin yang sering dilakukan dan relative lebih mudah diaplikasikan. Metode natif dilakukan dengan cara feses diambil sedikit dan dioleskan pada object glass serta diberikan satu-dua tetes air lalu diratakan, tutup dengan cover glass dan kemudian periksa dengan mikroskop perbesaran 100×. Dalam pemeriksaan metode sedimentasi dilakukan dengan cara membuat suspensi feses dengan air perbandingan 1:10, lalu disaring dan filtrate dimasukkan dalam tabung sentrifus dan disentrifugasi kecepatan 1500 RPM selama 2-5 menit, supernatant dibuang dan diulang sampai jernih. Setelah jernih, supernatant dibuang dan endapan diaduk, endapan diambil sedikit dengan pipet Pasteur dan teteskan di object glass ditutup cover glass, sampel 
Ridwan et al. MKH (2021). 105-113

DOI: $10.20473 / \mathrm{mkh} . v 32 \mathrm{i} 3.2021 .105-113$

diperiksa dengan mikroskop perbesaran 100× (Sosiawati et al., 2017).

\section{Analisis Data}

Data diolah dengan rumus prevalensi dan dianalisis menggunakan analisis deskriptif kualitatif. Rumus Prevalensi (Murtidjo, 1994) adalah sebagai berikut:

$$
\text { Prevalensi }=\frac{\text { Jumlah Sampel yang Terinfeksi }}{\begin{array}{c}
\text { Jumlah Keseluruhan Sampel } \\
\text { yang Diperiksa }
\end{array}} \times 100
$$

\section{HASIL DAN PEMBAHASAN}

Berdasarkan hasil pemeriksaan laboratorium terhadap sampel feses dari 105 ekor kerbau di Kecamatan Candung, Kecamatan Ampek Angkek, dan Kecamatan Tilatang Kamang dengan menggunakan metode natif (sederhana) dan sedimentasi sederhana diperoleh hasil bahwa 25 ekor kerbau dinyatakan terinfeksi oleh fascioliasis, hasil tersebut dapat dilihat pada Gambar 1.

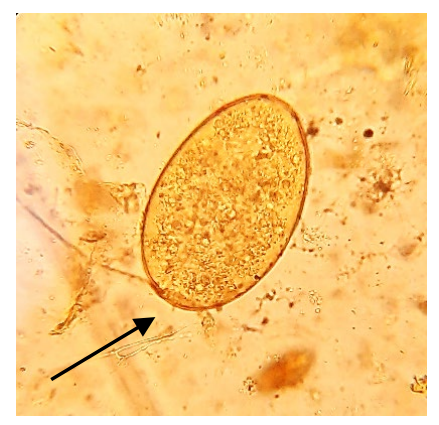

Gambar 1. Telur cacing Fasciola spp. dari sampel feses kerbau, perbesaran 400x dengan metode sedimentasi.
Telur cacing Fasciola spp. yang diperoleh pada Gambar 1. Tampak memiliki operculum di salah satu kutubnya (ditunjuk tanda panah), dan memiliki sel embrional yang kurang jelas serta hampir memenuhi rongga telur. Hasil serupa juga ditemukan pada peternakan sapi di daerah Tanggerang bahwa morfologi telur Fasciola spp. memiliki kerabang telur yang tipis, berbentuk ovoid, dan memiliki operculum disalah satu kutubnya (Majawati dan Matatula, 2018).

Pada pemeriksaan laboratorium, telur cacing Fasciola spp. dan Paramphistomum spp. sering kali dikelirukan, karena memiliki ukuran dan ciri-ciri morfologis yang hampir sama. Selain itu infeksi yang disebabkan oleh Fascioliasis sering disertai dengan infeksi cacing rumen seperti Paramphistomum spp. (Rozi et al., 2015). Namun permasalahan tersebut dapat diatasi dengan adanya modifikasi penambahan larutan methylene blue pada pemeriksaan feses (Budiono et al., 2018). Hal tersebut menyebabkan telur fasciola spp. akan tetap berwarna kuning dan telur paramphistomum spp. akan menyerap warna biru dari methylene blue, dikarenakan dinding telur paramphistomum spp. lebih tipis dari pada dinding telur Fasciola spp, tetapi dalam penelitian ini tidak dilakukan modifikasi tersebut.

Prevalensi Fasciola spp. secara keseluruhan pada penelitian ini diperoleh sebesar 23,81\% (25/105). 
Ridwan et al. MKH (2021). 105-113

DOI: $10.20473 / \mathrm{mkh} . \mathrm{v} 32 \mathrm{i} 3.2021 .105-113$

Hasil prevalensi ini lebih tinggi dibandingkan prevalensi pada kerbau di desa Jati Mulyo Kecamatan Jati Agung sebesar 6,25\% dari 30 ekor kerbau di Kabupaten Lampung Selatan (Ermawati et al., 2020), dan lebih rendah dari prevalensi Fasciola sp. pada kerbau di Provinsi Sulawesi Tengah yaitu sebesar 75,00\% (Budiono et al., 2018).

Besarnya angka prevalensi pada penelitian ini diperkirakan karena penerapan manajemen pemeliharaan yang buruk, seperti terkontaminasinya pakan oleh metaserkaria infektif serta sanitasi lingkungan yang kurang memadai (Levine, 1990). Terkontaminasinya pakan oleh metaserkaria tidak lepas dari peranan siput Lymnaea rubiginosa dan Lymnaea javanica yang menjadi inang perantara dari kehidupan Fasciola spp. (Kusnoto et al., 2011), dan siput ini umum ditemukan di Indonesia yang menjadi inang perantara Fasciola gigantica dan banyak ditemukan di lokasi penelitian karena mayoritas wilayahnya terdiri dari persawahan.

Prevalensi Fasciola spp. menurut karakteristik sampel, berdasarkan lokasi diperoleh Kecamatan Candung 11,43\%, Kecamatan Ampek Angkek $5,71 \%$, dan Kecamatan Tilatang kamang $54,29 \%$. Berdasarkan jenis kelamin diperoleh jantan 20,69\% dan betina $25 \%$. Berdasarkan umur diperoleh 0-2 tahun $16,67 \%$ dan $>2$ tahun $28,57 \%$. Berdasarkan sistem pemeliharaan diperoleh ekstensif 45,45\%, semi intensif $10 \%$, dan intensif $54,17 \%$. Berdasarkan tipe lantai diperoleh lantai tanah $25,71 \%$, bambu $18,18 \%$, dan beton 23,73\%. Prevalensi berdasarkan karakteristik sampel dapat dilihat pada Tabel 1.

Tabel 1. Prevalensi Fasciola spp. berdasarkan karakteristik sampel.

\begin{tabular}{cccc}
\hline & Karakteristik Sampel & Jumlah Sampel & Persentase \\
\hline \multirow{4}{*}{ Lokasi } & Candung & $4 / 35$ & $11,43 \%$ \\
& Ampek Angkek & $2 / 35$ & $5,71 \%$ \\
& Tilatang Kamang & $19 / 35$ & $54,29 \%$ \\
& Total & $\mathbf{2 5 / 1 0 5}$ & $\mathbf{2 3 , 8 1 \%}$ \\
\hline \multirow{3}{*}{ Jenis Kelamin } & Jantan & $6 / 29$ & $20,69 \%$ \\
& Betina & $19 / 76$ & $25 \%$ \\
& Total & $\mathbf{2 5 / 1 0 5}$ & $\mathbf{2 3 , 8 1 \%}$ \\
\hline \multirow{2}{*}{ Umur } & $0-2$ tahun & $7 / 42$ & $16,67 \%$ \\
& $>2$ tahun & $18 / 63$ & $28,57 \%$ \\
& Total & $\mathbf{2 5 / 1 0 5}$ & $\mathbf{2 3 , 8 1 \%}$ \\
\hline \multirow{3}{*}{ Sistem Pemeliharaan } & Ekstensif & $5 / 11$ & $45,45 \%$ \\
& Semi Intensif & $7 / 70$ & $10 \%$ \\
& Intensif & $13 / 24$ & $54,17 \%$ \\
& Total & $\mathbf{2 5 / 1 0 5}$ & $\mathbf{2 3 , 8 1 \%}$ \\
\hline \multirow{2}{*}{ Tipe Lantai } & Tanah & $9 / 35$ & $25,71 \%$ \\
& Bambu & $2 / 11$ & $18,18 \%$ \\
& Beton & $14 / 59$ & $23,73 \%$ \\
& Total & $\mathbf{2 5 / 1 0 5}$ & $\mathbf{2 3 , 8 1 \%}$ \\
\hline
\end{tabular}

(C)2021.Ridwan et al. Open access under CC BY-SA license, doi:10.20473/mkh.v32i3.2021.105-113 Received: 21-06-2021, Accepted: 01-07-2021, Published online: 08-09-2021

Available at https://e-journal.unair.ac.id/MKH/index 
Berdasarkan lokasi pengambilan sampel tampak Kecamatan Tilatang Kamang memiliki angka prevalensi Fasciola spp. yang lebih tinggi dari pada kecamatan lainnya yaitu sebesar $54,29 \%$. Hal ini mungkin terjadi disebabkan oleh geografis wilayah Tilatang Kamang yang lembab dan mayoritas terdiri dari persawahan sehingga cocok untuk perkembangan siput sebagai inang perantara dari Fasciola spp. Kondisi iklim seperti temperature $23^{\circ}-26^{\circ} \mathrm{C}$, $\mathrm{pH}$ 7,5-8,0, kelembaban (lembab dan sedikit hangat) dan kebutuhan oksigen yang sedikit juga akan mempermudah proses perkembangan dan penetasan telur Fasciola spp. (Kusnoto dkk., 2011).

$$
\text { Prevalensi Fasciola spp. }
$$

berdasarkan jenis kelamin diperoleh paling tinggi pada betina sebesar $25 \%$. Hasil yang sama juga diperoleh pada penelitian Bhutto et al. (2012) di Pakistan lebih tinggi pada kerbau betina. Tingginya prevalensi pada ternak betina dari pada jantan tidak dapat dijelaskan secara tepat tetapi dapat diasumsikan karena pengaruh hormonal dan stress akibat adanya birahi, masa bunting, melahirkan, dan laktasi yang mengarah terhadap penekanan kekebalan tubuh (Karim et al., 2015). Kejadian ini juga diperburuk ketika kebutuhan energi ternak betina yang tinggi tidak tercukupi dengan maksimal (Deeba et al., 2019).

Menurut perkiraan umur, prevalensi Fasciola spp. lebih tinggi pada umur $>2$ tahun yaitu sebesar
28,57\%. Meningkatnya penyakit parasit juga diiringi dengan bertambahnya usia artinya makin tua umur ternak maka makin tinggi prevalensi intensitas parasitnya, hal itu diperkirakan karena ternak yang muda (umur 0-12 bulan) memiliki frekuensi memakan rumput lebih rendah bahkan masih ada yang memperoleh nutrisi dari induk, sedangkan ternak dewasa rentan dari pemberian pakan hijauan segar dengan frekuensi yang banyak dan terus menerus sehingga memberikan peluang besar untuk transmisi Fasciola spp. (Hambal et al., 2013; Satyawardana et al., 2018). Selain itu ternak dewasa juga dipekerjakan lebih berat sehingga sering stress menyebabkan penurunan kekebalan sistem imun (Anggraini et al., 2019).

Prevalensi Fasciola spp. berdasarkan sistem pemeliharaan diperoleh pemeliharaan intensif memiliki angka prevalensi yang paling besar yaitu 54,17\%. Tingginya prevalensi pada pemeliharaan intensif dapat diakibatkan oleh stress, sebab sifat alamiah kerbau yang sering berendam di dalam lumpur dibatasi sehingga akan mendukung percepatan infeksi. Dimana hasil yang sama juga diperoleh pada penelitian Ermawati et al (2020) tingginya prevalensi Fasciola spp. pada pemeliharaan intensif karena ternak tidak digembalakan dan pemberian pakan hanya dilakukan di dalam kandang.

Apabila dilihat dari kondisi tipe lantai diperoleh bahwa prevalensi pada 
lantai tanah memiliki angka yang paling tinggi yaitu $25,71 \%$ tetapi menurut Purwaningsih et al (2017) kondisi lantai kandang tidak berpengaruh signifikan terhadap kejadian fascioliasis. Namun tingginya prevalensi pada lantai tanah dimungkinkan karena kerbau yang selalu defekasi dibiarkan begitu saja oleh peternak menyebabkan kerbau tidur bersamaan dengan feses. Hal seperti ini didukung dengan pengambilan sampel bertepatan dengan musim penghujan menyebabkan kandang menjadi becek, lembab, dan tergenang air yang memungkinkan kontaminasi telur cacing Fasciola spp. Terhadap lingkungan lebih tinggi. Kandang yang kotor dan tergenang air juga menyediakan tempat bagi siput dalam perkembangan mirasidium (Siswantoet al., 2018).

\section{KESIMPULAN}

Berdasarkan hasil penelitian dapat disimpulkan bahwa 25 ekor dari 105 ekor kerbau di Kabupaten Agam Provinsi Sumatra Barat dinyatakan positif terinfeksi Fasciola spp. Prevalensi Fasciola spp. yang diperoleh secara keseluruhan adalah 23,81\% (25/105), dan hasil yang diperoleh dapat menjadi potensi untuk dikembangkan dalam penelitian lebih lanjut.

\section{UCAPAN TERIMA KASIH}

Penulis mengucapkan terima kasih kepada UPT Puskeswan Magek dan UPT Puskeswan Koto Hilalang yang telah membantu penulis untuk memperoleh data dalam pelaksanaan penelitian.

\section{DAFTAR PUSTAKA}

Anggraini, M., H. Primarizky, Mufasirin, L. T. Suwanti, P. Hastutiek dan S. Koesdarto. 2019. Prevalensi Penyakit Penyakit Protozoa Darah pada Sapi dan Kerbau di Kecamatan Moyo Hilir Kabupaten Sumbawa Nusa Tenggara Barat. Journal of Parasite Science. 3(1): 9-14.

Bhutto, B., A. Arijo, M. S. Phullant and R. Rind. 2012. Prevalence of Fascioliasis in Bufalloes under Different Climatic Areas of Sindh Province of Pakistan. International Journal of Agriculture \& Biology. 14(2): 241-245.

BPS Indonesia. 2020. Statistik Indonesia

Statistical Yearbook of Indonesia 2020.

https://www.bps.go.id/publication/2 020/04/29/e9011b3155d45d70823c

141f/statistik-indonesia-2020.html.

Budiono, N. G., F. Satrija, Y. Ridwan, D.

Nur dan Hasmawati. 2018.

Trematodosis pada Sapi dan Kerbau di Wilayah Endemik 
Ridwan et al. MKH (2021). 105-113

DOI: $10.20473 / \mathrm{mkh} . v 32 \mathrm{i} 3.2021 .105-113$

Schistosomiasis di Provinsi Sulawesi Tengah, Indonesia. Jurnal Ilmu Pertanian Indonesia (JIPI). 23(2): 112-126.

Deeba. F., A. S. Qureshi, A. R. Kashif and I. Saleem. 2019. Epidemiology of different gastrointestinal helminths in buffaloes in relation to age, sex and body condition of the host. Journal of Entomology and Zoology Studies. 7(1): 1533-1540.

Ermawati. R., M. Hartono, P. E. Santosa dan M. M. P Sirat. 2020. Prevalensi Cacing Hati (Fasciola sp.) pada Kerbau Lumpur (Bubalus bubalis Linn.) di Kecamatan Jati Agung Kabupaten Lampung Selatan. Prosiding Seminar Nasional Teknologi Peternakan dan Veteriner Virtual 2020. TPV2020-p: 405-415.

Hambal. M., A. Sayuti dan A. Dermawan. 2013. Tingkat Kerentanan Fasciola gigantica pada Sapi dan Kerbau di Kecamatan Lhoong Kabupaten Aceh Besar. Jurnal Medika Veterinaria. 7(1): 49-53.

Karim, Md. R., M. S. Mahmud and Md.

Giasuddin. 2015. Epidemiological Study of Bovine Fasciolosis: Prevalence and Risk Factor Assessment at Shahjadpur Upazila of Bangladesh. Immunology and Infectious Diseases. 3(3): 25-29.
Karim, W. A., A. Farajallah and B. Suryobroto. 2016. Exploration and prevalence of gastrointestinal worm in buffalo from West Java, Central Java, East Java and Lombok, Indonesia. Aceh Journal of Animal Science. 1(1): 1-15.

Khairiyah. 2011. Zoonosis dan Upaya Pencegahannya (Kasus Sumatra Utara). Jurnal Litbang Pertanian. 30(3): 117-124.

Kusnoto., S. Subekti, S. Koesdarto dan S. M. Sosiawati. 2011. Buku Ajar Ilmu Penyakit Helmint. Pusat Penerbitan dan Percetakan Universitas Airlangga. Surabaya.

Levine, N. D. 1990. Buku Pelajaran Parasitologi Veteriner (terjemahan) edisi kedua. Gajah Mada University Press. Yogyakarta.

Majawati, E. S dan A. E. Matatula. Identifikasi Telur Cacing Fasciola Hepatica pada Sapi di Peternakan Sapi Daerah Tanggerang. Jurnal Kedokeran Meditek. 24(68): 6066.

Murtidjo, B.A. 1994. Metode Riset Epidemiologi. Gadjah Mada University Press. Yogyakarta.

Pandya, S. S., J. J. Hasnani, P. V. Patel, V. D. Chauchan, N. D. Hirani, R. Shukla and H. B. Dhamsaniya. 2015. Study on prevalence of Fasciolosis in bufalloes at Anand and Ahmedabad districts, 
Gujarat, India. Vet World. 8(7): 870-874.

Purwaningsih, Noviyanti dan R.P. Putra. 2017. Distribusi dan Faktor Risiko Fasciolosis pada Sapi Bali di Distrik Prafi, Kabupaten Manokwari, Provinsi Papua Barat. Acta Veterinaria Indonesiana.5 (2): 120-126.

Rana, M. A. A., N. Roohi and M. A. Khan. 2018. Fascioliasis in Cattle - A Review. The Journal of Animal \& Plant Sciences. 24(3): 668-675.

Rozi, F., J. Handoko dan R. Febriyanti. 2015. Infestasi Cacing Hati (Fasciola sp.) dan Cacing Lambung (Paramphistomum sp.) pada Sapi Bali Dewasa di Kecamatan Tenayan Raya Kota Pekan Baru. Jurnal Sains Veteriner. 33(1): 8-15.

Satyawardana, W., Y. Ridwan dan F. Satrija. 2018. Trematodosis pada Sapi Potong di Wilayah Sentra Peternakan Rakyat (SPR) Kecamatan Kasiman, Kabupaten Bojonegoro. Acta Veterinaria Indonesiana. 6(2): 1-7.

Siswanto., M. Hartono, P. E. Santosa, S. Surhayati, H. Larasati dan M. M. P. Sirat. 2018. Prevalensi Cacing Hati Sapi Perah pada Peternakan Rakyat di Provinsi Lampung. Jurnal Ilmiah Peternakan Terpadu. 6(3): 167172.

Sosiawati, S. M., S. Koesdarto, S. S. Bendryman dan Kusnoto. 2017.
Penuntun Praktikum Ilmu Penyakit Helminth Veteriner. Fakultas Kedokteran Hewan Universitas Airlangga. Surabaya.

Umar, H. 2002. Metode Riset Bisnis. PT. Gramedia Pustaka Utama. Jakarta.

Widjajanti, 2004. Fascioliasis pada Manusia: Mungkinkah Terjadi di Indonesia?. Wartazoa. 14(2): 65-72.

Yadav, S. K., MD. Ahaduzzaman, S. Sarker, MD. A. Sayeed and MD. A. Hoque. 2015. Epidemiological Survey of Fascioliasis in Cattle, Buffalo and Goat in Mahottari and Dhanusha, Nepal. The Journal of Advances in Parasitology. 2(3): 52-56. 